\title{
Factor Structure and Measurement Invariance Between Fathers and Mothers and Across Three Time Points After Childbirth: Identification of Core Items of The Japanese Version of The Mother-To-Infant Bonding Scale
}

Kaori Baba ( $\nabla$ kaoribaba@scln.ac.jp )

St Luke's International University

Yaeko Kataoka

St Luke's International University

Toshinori Kitamura

Kitamura Institute of Mental Health Tokyo

\section{Research Article}

Keywords: bonding disorder, postpartum, mother-to-infant bonding scale, longitudinal study, factor analysis, measurement invariance

Posted Date: October 29th, 2021

DOI: https://doi.org/10.21203/rs.3.rs-1006778/v1

License: (c) (1) This work is licensed under a Creative Commons Attribution 4.0 International License. Read Full License 


\section{Abstract \\ Background}

The Japanese version of the mother-to-infant bonding scale (MIBS-J), a self-report of postnatal bonding disorder, is widely used in Japan. However, its psychometric properties, particularly measurement invariance, have rarely been reported, and the appropriateness of the use of the MIBS-J among perinatal fathers remains to be investigated. This study aimed to select and to validate MIBS-J items suitable for mothers and fathers at three time points (postpartum hospitalization period and 1 and 4 months postpartum) commonly used in clinical practice in Japan.

\section{Methods}

Postpartum mothers $(n=543)$ and fathers $(n=350)$ were surveyed at 5 days, 1 month, and 4 months postpartum. All participants were randomly divided into two subgroups, one for exploratory factor analyses (EFAs) and another for confirmatory factor analyses. Measurement invariance of the best model was tested using the entire sample, between fathers and mothers, and across the three observation periods.

\section{Results}

A three-item structure (items 1, 6, and 8) extracted through EFAs showed acceptable configural invariance. This model was accepted for scalar invariance between fathers and mothers and for metric invariance across the three time points.

\section{Conclusions}

This study showed that the three-item MIBS-J could be used reliably among Japanese parents in the first four postpartum months. Currently, all 10 MIBS-J items are used in clinical and research settings at various time points during the perinatal period. Our findings suggest that the MIBS-J with only three items is sufficient for diagnosis of postnatal bonding disorder, at least during the first four postpartum months.

\section{Background}

Parental emotional ties toward a child, particularly an infant, are termed bonding. Perinatal psychiatry cast light on parental bonding in the 1990s. There are mothers who experience dislike, resentment or hatred, and/or desire for permanent abandonment toward their infant and hope for the child to disappear [1, 2]. Bonding disorders toward infants may have serious and long-term consequences for the child's development and mother-child relationship [3]. An international position paper on mother-infant (perinatal) mental health [4] notes that "a small minority of mothers may suffer from emotional rejection of the infant, which, together with psychosis and suicidal depression, is in the first rank of severity in this area of psychiatry."

There are self-report instruments to measure parental (particularly maternal) bonding disorders. One of them is the mother-toinfant bonding scale (MIBS) [5]. A Japanese modification of the MIBS (MIBS-J), developed by Yoshida et al. [6], has been widely used in clinical and research settings in Japan (e.g., Ohashi et al. [7] and Baba et al. [8]). However, caution is required when the MIBS- $J$ is used in research settings. First, the MIBS- $J$ is often repeatedly used routinely across short periods of time for individual women (e.g., during postnatal hospitalization, 1-month check-ups, and 4-month infant check-ups). However, the repeated use of a psychological measure is usually accompanied by reduced validity $[9,10,11]$, and the appropriateness of using all the items of the MIBS-J at multiple time points is not clear. Second, bonding disorders are not only a problem for mothers, and bonding research should also focus on fathers [12-18]. Currently, only mothers have been included in many studies. Thus, the target should be expanded to include fathers. However, the appropriateness of the use of the MIBS-J among perinatal fathers remains to be investigated. Third, some of the 10 MIBS-J items are quite highly skewed $[6,14]$. Consequently, 
most of the general population of parents would report "no problem" to these items. Indeed, there may be little clinical significance in using all 10 items for all cases, as is currently the case.

These methodological issues require validation and sophistication of the MIBS-J factor structure. The MIBS-J factor structure has been reported in at least two studies [6, 14]. Yoshida et al. conducted a longitudinal study of postpartum mothers $(n=554)$ and collected responses at three different time points: 5 days, 1 month, and 4 months after childbirth [6]. They found that seven, eight, and seven MIBS-J items showed skewness $>2.0$ at 5 days, 1 month, and 4 months after childbirth, respectively, although there was no skewness of the MIBS-J items after log-transformation. They further conducted combined exploratory and confirmatory factor analyses (EFAs and CFAs, respectively), and a two-factor structure (lack of affection [LA] and anger and rejection [AR]) was extracted. However, this procedure might have blurred the differences in terms of the factor structure of the scale across the time periods because the data obtained from the three time points were combined to create a single data set. Subsequently, separate CFAs were conducted for the data from the three time points. Acceptable fitness of the model was found with the data at 5 days after childbirth (comparative fit index $[\mathrm{CFI}]=.922$ ). However, fitness was far less than required $(\mathrm{CFI}>$.95) [19] at $1(\mathrm{CFI}=.889)$ and $4(\mathrm{CFI}=.905)$ months after childbirth. Scrutinizing items one by one separately revealed that standardized factor loading was 0.09 for item 2 ("scared or panicky") at five days after childbirth and 0.29 for item 7 ("wish baby was different") at one month after childbirth. These findings suggest that the factor structure of this model might differ across the three time points. The means of the two subscale scores decreased with time; however, Yoshida et al. did not measure the factor mean invariance across the time points [6]. A few years later, Kitamura et al. collected data using the MIBS-J from a cross-sectional sample of fathers $(n=396)$ and mothers $(n=733)$ with children aged 0 to 10 years [14]. They identified a two-factor structure of the MIBS-J items, which was quite similar to that reported by Yoshida et al. [6]. They found a good fit of the model with the data in terms of configural invariance $(\mathrm{CFI}=.956$ and root mean square error of approximation [RMSEA] = 0.033). However, they did not report on measurement invariance.

The use of a psychological measure requires confirmation of configural, measurement, and structural invariance of the factor structure of the measure. Thus, the factor structure of the measure should be stable between participants with different demographic features (e.g., fathers and mothers), as well as across various observation time points. If these assumptions do not hold, items of the measure do not have the same meaning and may cause bias in the assessment, and a comparison of the measured scores does not make any sense. The stability of the factor structure is confirmed through several steps [20], and the subsequent steps are endorsed only when the preceding steps are accepted. If one step is rejected, the next step should not be performed. Basic stability is termed configural invariance. Each group (e.g., fathers vs. mothers) should have the same pattern of items and factors (first step). Moreover, factor loadings for similar items (metric invariance, also known as weak factorial invariance; second step), intercepts of similar items (scalar invariance, also known as strong factorial invariance; third step), residuals (errors) of similar items (residual invariance, also known as strict factorial invariance; fourth step), variances of similar factors (factor variance invariance; fifth step), and the means of factors (factor mean invariance; sixth step) should be invariant across groups. The second to fourth steps are termed measurement invariance, and the fifth and sixth steps are termed structural invariance.

Such confirmation mentioned above is necessary for the MIBS-J to be used in clinical and research settings. This study aimed to select and to validate MIBS-J items suitable for mothers and fathers at the three time points (postpartum hospitalization period and 1 and 4 months postpartum) commonly used in clinical practice in Japan to enable a continuous assessment of bonding disorders among perinatal mothers and fathers over time and to minimize the burden on respondents.

\section{Methods}

\section{Procedures and participants}

We recruited mothers and fathers on days 3-5 postpartum at the maternity ward of one perinatal medical center, three general hospitals, two antenatal clinics, and one birth center in Tokyo and its suburban areas. The inclusion criteria were as follows: (a) a good command of the Japanese language, (b) residing in Japan, (c) having no serious physical diseases or pregnancyrelated complications, and (d) a singleton neonate. One of the investigators (KB) visited the wards and recruited participants 
after explaining the study and obtaining informed consent from the participants. Data were collected in three waves: 5 days (Wave 1, W1), 1 month (Wave 2, W2), and 4 months (Wave 3, W3) after childbirth. The numbers of fathers and mothers who returned the questionnaire were respectively 421 and 684 at W1, 361 and 590 at W2, and 351 and 566 at W3. We handed (W1) or posted (W2 and W3) the set of questionnaires to the participants and asked them to return them via the postal service. Mothers and fathers were asked to complete the questionnaire independently. Data were collected from December 2015 to June 2016 as part of the first author's PhD dissertation [21]. The mean (standard deviation) age of the mothers and fathers was 33.1 (4.7) and $34.6(5.1)$ years, respectively. More than three-quarters $(n=437)$ of the mothers underwent vaginal delivery, and $18 \%(n=98)$ of them underwent Cesarean delivery. There were $288(53 \%)$ primiparas and $253(47 \%)$ multiparas.

\section{Measurement}

\section{Mother-to-infant bonding disorder}

The MIBS-J comprises 10 items that assess mothers' attitudes and emotions toward their infants [6]. These items are rated on a 4-point Likert scale (0-3), and higher scores indicate that the mother has a more negative attitude and emotion toward the infant. Two subscales were proposed by Yoshida et al. and Kitamura et al. [6, 14]: LA and AR. LA items include "feel protective toward my baby" (reverse item) and "feel close to my baby" (reverse item), whereas AR items include "feel angry with my baby" and "feel resentful toward my baby." We used the same questionnaire for the fathers.

\section{Data analysis}

The participants who returned the questionnaire at all three time points (350 fathers and 543 mothers) were randomly split into two subgroups. The first (166 fathers and 282 mothers) and second (184 and 261 mothers) groups were used for EFAs and CFAs, respectively. Missing MIBS-J data were considered to be missing completely at random (Little's missing completely at random test for fathers $[p=.582]$ and mothers $[p=.229])$. The missing data were handled by pairwise deletion for all analyses, except for CFAs. For CFAs, the missing data were handled using the full information maximum likelihood method.

In an EFA using the first half sample, we calculated the skewness and kurtosis of all the MIBS-J items. When excessive skewness or kurtosis was present, the MIBS-J items were log-transformed. Items that showed excessive skewness (>4.0) or kurtosis (> 15.0), even after log-transformation, were excluded from further analyses. We performed EFAs for the remaining items after conforming to the Kaiser-Meyer-Olkin index of sampling adequacy [22] and Bartlett's test of sphericity [23] to examine the adequacy of the sample size and non-zero correlations between items [24]. The number of factors was determined using a scree plot. The minimum acceptable factor loading was 0.30 [25], maximum likelihood extraction was performed, and the axes were rotated using Promax rotation.

Next, using the second half of the sample, CFAs were performed to obtain the adequate MIBS-J model extracted by the EFAs. Measures of goodness-of-fit were chi-square (CMIN), CFI, and RMSEA. A good fit was defined as CMIN/ $d f<2, \mathrm{CFI}>.97$, and RMSEA $<0.05$ [26], and an acceptable fit was defined as CMIN/ $d f<3, \mathrm{CFI}>.95$, and RMSEA $<0.08$ [26, 27]. However, when the sample size is relatively small $(<500)$ or a model is complex, these criteria might be stringent, and the use of more flexible criteria is suggested (e.g., CFI > .90 and RMSEA < 0.10 [28]). We also considered these flexible criteria when examining model fit.

Measurement invariance of the best model was tested with the full sample (participants who returned the questionnaire at all three time points; 350 fathers and 543 mothers), between fathers and mothers, and across the three observation periods. A series of hierarchical models was tested as follows. First, configural invariance was tested. Once configural invariance was supported, which indicates that both sexes or periods share the same factor structure, metric invariance was tested. When metric invariance was held, which indicates that the factor loadings were equivalent across sexes or periods, scalar invariance was assessed by restricting the item intercepts to be equal across sexes or periods. When scalar invariance was supported, a comparison of residual invariance between sexes and periods was implemented to examine residual invariance. In addition, structural invariance was needed as evidence of factor structure robustness, and it included factor variance invariance. If one of the above steps was rejected, subsequent steps were not performed. Invariance from one step to the next was "accepted" if 
we noticed either (a) a non-significant increase in $\chi^{2}$ for $d f$ of difference, (b) a less than 0.01 decrease in the CFI, or (c) a less than 0.01 increase in the RMSEA $[29,30]$. The CFI and RMSEA may be better indicators of measurement invariance than $\chi^{2}$ because $\chi^{2}$ is sensitive to the sample size and may thus produce excessive "rejection" rates. In addition, since scalar-level measurement invariance is rarely confirmed [31] and there is no consensus on the level to which it should be confirmed, we considered measurement invariance to be present if it is confirmed up to at least metric invariance. To determine measurement invariance, a distinction was made between full and partial invariance [20,32,33].

All statistical analyses were conducted using IBM SPSS 26 and Amos 26 (IBM Corp., Armonk, NY, USA).

\section{Ethical consideration}

This study was approved by the Ethical Committee of St. Luke's International University (15-074).

\section{Results}

\section{Factor structure derived from EFA}

In the first half group, many MIBS-J items showed high skewness and kurtosis (Table 1). Skewness and kurtosis were less severe after log transformation; however, there were still five items (items 3, 4, 5, 7, and 9) with skewness > 4.0 and kurtosis > 15.0. Hence, we excluded those five items, and the remaining five MIBS-J items were entered into an EFA. The Kaiser-MeyerOlkin index was 0.74-0.75, and the Bartlet test was $\chi^{2}(d f)=171.99(10)-337.98(10)(p<.001)$. Therefore, the datasets were suitable for EFAs. The EFAs for the fathers and mothers were performed separately. The scree test suggested either one- or twofactor solution for both fathers and mothers. In the one-factor model, all the MIBS-J items, except item 2, showed factor loadings $>0.3$ at all three time points (Supplementary Table 1, Additional File 1). In the two-factor solution, the first factor was loaded highly ( $>0.3$ ) on MIBS-J items $1,6,8$, and 10, which reflect LA, as demonstrated in previous studies [6,14]. The second factor was loaded highly on only item 2, which reflects AR. We excluded this item from further analyses because a factor with only a single indicator having a high factor loading is unstable for a measurement model.

The remaining four MIBS-J items (items 1, 6, 8, and 10) belonged to the LA category. A single factor EFA showed high factor loadings for all items at all time points among both fathers and mothers (Table 2).

\section{Measurement invariance across sexes or periods of time}

When comparing the factor models between fathers and mothers, configural invariance was accepted. However, metric invariance was rejected for W3 (Supplementary Table 2, Additional File 2). Therefore, we examined the $z$ value, which indicates the group differences in the factor loadings, and found that item 10 showed the largest group difference $(z=3.165, p<.01)$. Therefore, after excluding item 10, we re-examined the EFA and configural invariance (Table 3).

The remaining model had a three-item structure (items 1,6 , and 8). When comparing this model between fathers and mothers, configural invariance was confirmed at all three time points. Measurement invariance also conformed to the stability of factor variance at W1 and W2 and up to scalar invariance at W3 (Table 4).

When comparing the three time points, configural invariance was confirmed in both fathers and mothers (Table 5). Among fathers, metric invariance was rejected, although partial invariance was supported by freeing the restriction of item 6 .

Subsequently, scalar invariance was accepted. Among mothers, metric invariance was proven. Scalar invariance was rejected in both fathers and mothers (Table 5).

\section{Discussion}

In this study, configural and measurement invariance between mothers and fathers and across three postnatal time points was observed using only three MIBS-J items. This finding does not echo that in other studies of the two-factor MIBS-J structure among Japanese mothers after childbirth [6] or parents with children aged $\leq 12$ years [14]. All three remaining items belonged 
to LA. All the items belonging to AR were deleted because of excessive skewness/kurtosis or instability of the measurement model. Unlike LA items, AR items are likely to be influenced by some situations, e.g., newborn colic [34, 35], which might have reduced the invariance of the instrument. Our findings highlight the importance of emphasizing affection items to measure parental bonding with stability during the first four postpartum months.

The use of the full 10-item version may be a burden on the participants and may result in score biases due to repeated measures. Notably, the three-item version may be much easier for perinatal health professionals, such as midwives and community nurses. Therefore, in clinical and research settings, it would be advisable to use the three MIBS-J items, rather than all 10 items, for continuous observation, assessment, and comparison of parental bonding, at least during the first 4 months after the birth of the infant.

The limitations of this study should be noted. First, this study included fewer fathers than mothers. Thus, replication studies are needed before a conclusion is reached. Second, several MIBS-J items showed skewness. This finding suggests that the selection of the participants may have been biased, and the study cohort included few poorly bonded participants. A population of clinical cases might produce different results. Third, according to a systematic review of scales measuring bonding [36], the psychometric evaluation performance of the MIBS-J is low. Although there are scales measuring paternal bonding (e.g., the Korean paternal-fetal attachment scale and paternal postnatal attachment scale), all have poor psychometric properties. It would be desirable to develop a scale with higher psychometric properties to measure parental bonding.

\section{Conclusions}

Our study confirmed that the three-item MIBS-J was psychometrically robust among Japanese fathers and mothers during the 4-month period after childbirth. All these three items belong to LA, as reported in previous studies [6, 14]. Thus, we believe that it is important to focus on affection to measure parental bonding with stability during the first four postpartum months using the MIBS-J. At present, all 10 MIBS-J items are used in clinical and research settings at various time points during the perinatal period. However, our findings suggest that the use of the MIBS-J with only three items is sufficient for at least the first 4 months of life. Therefore, considering the burden on participants, the MIBS-J with a reduced number of items should be suggested.

\section{List Of Abbreviations}

AR: anger and rejection

CFA: confirmatory factor analysis

CFI: comparative fit index

EFA: exploratory factor analysis

LA: lack of affection

MIBS: mother-to-infant bonding scale

MIBS-J: Japanese modification of the mother-to-infant bonding scale

RMSEA: root mean square error of approximation

W1: 5 days after childbirth

W2: 1 month after childbirth

W3: 4 months after childbirth

\section{Declarations}




\section{Ethics approval and consent to participate}

This study was approved by the Research Ethics Committee of St. Luke's International University (approval no. 15-074). All participants provided written informed consent after understanding the study rationale and procedure. The authors assert that all procedures contributing to this study complied with the ethical standards of the National and Institutional Committees on Human Experimentation and with the Helsinki Declaration of 1975 as revised in 2008.

\section{Consent for publication}

Not applicable.

\section{Availability of data and materials}

The datasets used and/or analyzed during the current study are available from the corresponding author on reasonable request.

\section{Competing interests}

The authors declare that they have no competing interests.

\section{Funding}

This study was supported by a MEXT KAKENHI grant (Number, 25293458; PI, Yaeko Kataoka) and a grant-in-aid from the Yamaji Fumiko Nursing Research Fund.

\section{Authors' contributions}

KB designed and coordinated this study, carried out the analysis and interpretation of the data, and drafted and revised the manuscript. TK contributed to data analysis and interpretation of the study findings and reviewed and revised the manuscript. YK participated in the design of this study and contributed to the interpretation of the study findings. All authors read and approved the final manuscript.

\section{Acknowledgments}

We are grateful to all participating parents and the staff of the antenatal clinics, and we are also grateful to Prof. Shigeko Horiuchi, president of St. Luke's International University, for valuable comments on the study design.

\section{References}

1. Brockington IF. Motherhood and mental health. Oxford: Oxford University Press; 1996.

2. Kumar RC. Anybodys child: severe disorders of mother-to-infant bonding. Br J Psychiatry. 1997;171:175-81. doi:10.1192/bjp.171.2.175.

3. Brockington IF, Oates J, George S, Turner D, Vostanis P, Sullivan M, et al. A screening questionnaire for mother-infant bonding disorders. Arch Womens Ment Health. 2001;3:133-40. doi:10.1007/s007370170010.

4. Brockington I, Butterworth R, Glangeaud-Freudenthal N. An international position paper on mother-infant (perinatal) mental health, with guidelines for clinical practice. Arch Womens Ment Health. 2017;20:113-20. doi:10.1007/s00737-016-0684-7.

5. Taylor A, Atkins R, Kumar R, Adams D, Glover V. A new Mother-to-Infant Bonding Scale: links with early maternal mood. Arch Womens Ment Health. 2005;8:45-51. doi:10.1007/s00737-005-0074-z.

6. Yoshida K, Yamashita H, Conroy S, Marks M, Kumar C. A Japanese version of Mother-to-Infant Bonding Scale: factor structure, longitudinal changes and links with maternal mood during the early postnatal period in Japanese mothers. Arch Womens Ment Health. 2012;15:343-52. doi:10.1007/s00737-012-0291-1. 
7. Ohashi Y, Sakanashi K, Tanaka T, Kitamura T. Mother-to-infant bonding disorder, but not depression, 5 days after delivery is a risk factor for neonate emotional abuse: a study in Japanese mothers of 1-month olds. Open Fam Stud J. 2016;8:27-36. doi:10.2174/1874922401608010027.

8. Baba K, Kataoka Y, Kitamura T. A discrete category of Japanese parents as neonatal abusers with perinatal bonding disorders: a three-month postnatal longitudinal study. In Kitamura T, Ohashi Y, editors. Perinatal bonding disorders: causes and consequences. Newcastle upon Tyne: Cambridge Scholars Publishing; 2019. p. 164-88.

9. Kitamura T, Shima S, Sugawara M, Toda MA. Temporal variation of validity of self-rating questionnaires: repeated use of the General Health Questionnaire and Zung's Self-rating Depression Scale among women during antenatal and postnatal periods. Acta Psychiatr Scand. 1994;90:446-50. doi: 10.1111/j.1600-0447.1994.tb01622.x.

10. Windle C. Test-retest effect on personality questionnaires. Educ Psychol Meas. 1954;14:617-33. doi:10.1177/001316445401400404.

11. Windle C. Further studies of test-retest effect on personality questionnaires. Educ Psychol Meas. 1955;15:246-53. doi:10.1177/001316445501500304.

12. Chen E-M, Gau ML, Liu CY, Lee TY. Effects of father-neonate skin-to-skin contact on attachment: a randomized controlled trial. Nurs Res Pract. 2017;2017:8612024. doi: 10.1155/2017/8612024.

13. Edhborg M, Matthiesen AS, Lundh W, Widström AM. Some early indicators for depressive symptoms and bonding 2 months postpartum: a study of new mothers and fathers. Arch Womens Ment Health. 2005;8:221-31. doi: 10.1007/s00737-005-0097-5.

14. Kitamura T, Takegata M, Haruna M, Yoshida Y, Yamashita H, Murakami M, et al. The Mother-Infant Bonding Scale: factor structure and psychosocial correlates of parental bonding disorders in Japan. J Child Fam Stud. 2013;24:393-401. doi:10.1007/s10826-013-9849-4.

15. Kitamura T, Ohashi Y, Murakami M, Goto Y. Bonding disorders, current adult attachment, and perceived rearing in childhood in parents of children aged 10 years old or younger: a structural equation model approach. In: Kitamura T, Ohashi Y, editors. Perinatal bonding disorders: Causes and consequences. Newcastle upon Tyne: Cambridge Scholars Publishing; 2019. p. 50-81.

16. Miriashali J, Holsti L, Ranjbar H, Sanjari M, Morovati F, Ameri ZD. The impact of involvement of father's with preterm newborns on their parent-infant bonding and self-efficacy: non-randomised clinical trial. Research Square. https://www.researchsquare.com/article/rs-35486/v1. Accessed 22 Oct 2021.

17. Parfitt V, Ayers S, Pike A, Jessop DC, Ford E. A prospective study of the parent-baby bond in men and women 15 months after birth. J Reprod Infant Psychol. 2012;32:441-56. doi: 10.1080/02646838.2014.956301.

18. Scism AR, Cobb RL. Integrative review of factors and interventions that influence early father-infant bonding. J Obstet Gynecol Neonatal Nurs. 2017;46:163-70. doi: 10.1016/j.jogn.2016.09.004.

19. Hu LT, Bentler PM. Cutoff criteria for fit indexes in covariance structure analysis: conventional criteria versus new alternatives. Struct Equ Modeling. 1999;6:1-55. doi:10.1080/10705519909540118.

20. Vandenberg RJ, Lance CE. A review and synthesis of the measurement invariance literature: suggestions, practices, and recommendations for organizational research. Organ Res Methods. 2000;3:4-70. doi:10.1177/109442810031002.

21. Baba K. Kouzouhouteishikimoderingu wo motiita nyuujigyakutai to kazokunai no youin no inngakouzou no tannsaku [Causal relationships between infant abuse and family factors using structural equation modeling]. (Unpublished doctoral dissertation). Tokyo: St. Luke's International University; 2016 (in Japanese).

22. Kaiser HF, Rise J. Little Jiffy, Mark IV. Educ Psychol Meas. 1974;34:111-7. doi:10.1177/001316447403400115.

23. Bartlett MS. A note on the multiplying factors for various $\chi^{2}$ approximations. J R Stat Soc Series B Stat Methodol. 1954;16:296-8. doi:10.1111/j.2517-6161.1954.tb00174.x.

24. Burton LJ, Mazerolle SM. Survey instrument validity part I: principles of survey instrument development and validity in athletic training education research. Athl Train Educ J. 2011;6:27-35. doi:10.4085/1947-380X-6.1.27. 
25. Yong AG, Pearce, S. A Beginner's guide to factor analysis: focusing on exploratory factor analysis. Tutor Quant Methods Psychol. 2013;9:79-94. doi:10.20982/tqmp.09.2.p079.

26. Schermelleh-Engell K, Moosbrugger $\mathrm{H}$, Müller $\mathrm{H}$. Evaluating the fit of structural equation models: tests of significance and descriptive goodnesss-of-fit measures. Methods Psychological Research Online. 2003;8:23-74.

27. Bentler PM. Comparative fit indexes in structural models. Psychol Bull. 1990;107:238-46. doi: 10.1037/00332909.107.2.238.

28. Weston R, Gore PA. A brief guide to structural equation modeling. Couns Psychol. 2006;34:719-51. doi:10.1177/0011000006286345.

29. Chen FF. Sensitivity of goodness of fit indexes to lack of measurement invariance. Struct Equ Modeling. 2007;14:464-504.

30. Cheung GW, Rensvold RB. Evaluating goodness-of-fit indexes for testing measurement invariance. Struct Equ Modeling. 2002;9:233-55.

31. Cieciuch J, Davidov E, Schmidt P, Algesheimer R. How to obtain comparable measures for cross-national comparisons. Köln Z Soziol. 2019;71:157-86. doi:10.1007/s11577-019-00598-7.

32. Byrne BM, Shavelson RJ, Muthén BO. Testing for the equivalence of factor covariance and mean structure: the issue of partial measurement invariance. Psychol Bull. 1989;105:456-66. doi:10.1037/0033-2909.105.3.456.

33. Steenkamp JB, Baumgartner H. Assessing measurement invariance in cross-national consumer research. J Consum Res. 1998;25:78-90. doi:10.1086/209528

34. Barr RG. Colic and crying syndromes in infants. Pediatrics. 1998;102:1282-6.

35. Barr RG, Trent RB, Cross J. Age-related incidence curve of hospitalized Shaken Baby Syndrome cases: convergent evidence for crying as a trigger to shaking. Child Abuse Negl. 2006;30:7-16. doi:10.1016/j.chiabu.2005.06.009.

36. Wittkowski A, Vatter S, Muhinyi A, Garrett C, Henderson M. Measuring bonding or attachment in the parent-infantrelationship: a systematic review of parent-report assessment measures, their psychometric properties and clinical utility. Clin Psychol Rev. 2020;82:101906. doi:10.1016/j.cpr.2020.101906.

\section{Tables}

Table 1 Paternal and maternal MIBS-J means, skewness, and kurtosis at W1, W2, and W3 


\begin{tabular}{|c|c|c|c|c|c|c|c|c|c|c|}
\hline \multicolumn{2}{|c|}{ Items } & Time & Sex & $\mathrm{n}$ & Mean & SD & Skewness & Kurtosis & Skewness & Kurtosis \\
\hline \multirow[t]{6}{*}{1} & \multirow{6}{*}{$\begin{array}{l}\text { I feel } \\
\text { loving } \\
\text { toward my } \\
\text { child }\end{array}$} & W1 & Fathers & 166 & 1.25 & 0.56 & 2.34 & 5.40 & 1.83 & 2.04 \\
\hline & & & Mothers & 281 & 1.19 & 0.48 & 2.97 & 10.18 & 2.25 & 4.04 \\
\hline & & W2 & Fathers & 166 & 1.30 & 0.56 & 1.70 & 1.94 & 1.37 & 0.31 \\
\hline & & & Mothers & 282 & 1.18 & 0.45 & 2.77 & 8.60 & 2.18 & 3.56 \\
\hline & & W3 & Fathers & 166 & 1.20 & 0.42 & 1.72 & 1.70 & 1.59 & 0.69 \\
\hline & & & Mothers & 282 & 1.11 & 0.36 & 4.08 & 20.39 & 3.20 & 9.71 \\
\hline \multirow[t]{6}{*}{2} & \multirow{6}{*}{$\begin{array}{l}\text { I feel } \\
\text { scared or } \\
\text { panicky } \\
\text { when I } \\
\text { have to do } \\
\text { something } \\
\text { for my } \\
\text { child }\end{array}$} & W1 & Fathers & 166 & 1.80 & 0.73 & 0.53 & -0.28 & -0.06 & -1.32 \\
\hline & & & Mothers & 279 & 1.76 & 0.84 & 0.89 & 0.01 & 0.32 & -1.29 \\
\hline & & W2 & Fathers & 165 & 1.64 & 0.73 & 0.77 & -0.40 & 0.35 & -1.42 \\
\hline & & & Mothers & 282 & 1.52 & 0.68 & 1.09 & 0.49 & 0.63 & -1.11 \\
\hline & & W3 & Fathers & 166 & 1.57 & 0.65 & 0.85 & 0.24 & 0.35 & -1.36 \\
\hline & & & Mothers & 282 & 1.34 & 0.62 & 1.97 & 4.13 & 1.32 & 0.47 \\
\hline \multirow[t]{6}{*}{3} & \multirow{6}{*}{$\begin{array}{l}\text { I feel } \\
\text { resentful } \\
\text { toward my } \\
\text { child }\end{array}$} & W1 & Fathers & 166 & 1.07 & 0.31 & 6.28 & 48.75 & 4.70 & 23.82 \\
\hline & & & Mothers & 281 & 1.12 & 0.38 & 4.22 & 23.10 & 3.06 & 9.15 \\
\hline & & W2 & Fathers & 166 & 1.20 & 0.52 & 3.05 & 10.64 & 2.26 & 4.21 \\
\hline & & & Mothers & 282 & 1.15 & 0.39 & 3.07 & 12.09 & 2.38 & 4.55 \\
\hline & & W3 & Fathers & 166 & 1.13 & 0.35 & 2.68 & 6.63 & 2.46 & 4.46 \\
\hline & & & Mothers & 282 & 1.13 & 0.49 & 4.61 & 22.76 & 3.63 & 13.18 \\
\hline \multirow[t]{6}{*}{4} & \multirow{6}{*}{$\begin{array}{l}\text { I feel } \\
\text { nothing } \\
\text { for my } \\
\text { child }\end{array}$} & W1 & Fathers & 166 & 1.05 & 0.22 & 4.26 & 16.32 & 4.26 & 16.32 \\
\hline & & & Mothers & 280 & 1.04 & 0.25 & 7.76 & 75.31 & 5.85 & 37.48 \\
\hline & & W2 & Fathers & 166 & 1.05 & 0.25 & 5.06 & 27.82 & 4.55 & 20.23 \\
\hline & & & Mothers & 282 & 1.05 & 0.30 & 8.07 & 73.18 & 6.46 & 45.03 \\
\hline & & W3 & Fathers & 166 & 1.02 & 0.25 & 11.38 & 135.35 & 10.32 & 111.38 \\
\hline & & & Mothers & 282 & 1.03 & 0.22 & 10.18 & 121.72 & 7.94 & 69.72 \\
\hline \multirow[t]{6}{*}{5} & \multirow{6}{*}{$\begin{array}{l}\text { I feel } \\
\text { angry with } \\
\text { my child }\end{array}$} & W1 & Fathers & 166 & 1.02 & 0.13 & 7.30 & 51.94 & 7.30 & 51.94 \\
\hline & & & Mothers & 281 & 1.04 & 0.21 & 5.87 & 37.63 & 5.33 & 28.12 \\
\hline & & W2 & Fathers & 166 & 1.05 & 0.25 & 5.06 & 27.82 & 4.55 & 20.23 \\
\hline & & & Mothers & 282 & 1.07 & 0.26 & 3.26 & 8.68 & 3.26 & 8.68 \\
\hline & & W3 & Fathers & 166 & 1.11 & 0.40 & 4.43 & 22.79 & 3.51 & 12.13 \\
\hline & & & Mothers & 282 & 1.07 & 0.31 & 5.45 & 37.04 & 4.23 & 18.41 \\
\hline \multirow[t]{3}{*}{6} & \multirow{3}{*}{$\begin{array}{l}\text { I enjoy } \\
\text { doing } \\
\text { things } \\
\text { with my } \\
\text { child }\end{array}$} & W1 & Fathers & 166 & 1.52 & 0.74 & 1.32 & 1.05 & 0.82 & -0.80 \\
\hline & & & Mothers & 279 & 1.65 & 0.76 & 0.93 & 0.19 & 0.39 & -1.28 \\
\hline & & W2 & Fathers & 166 & 1.72 & 0.85 & 0.93 & -0.04 & 0.42 & -1.30 \\
\hline
\end{tabular}




\begin{tabular}{|c|c|c|c|c|c|c|c|c|c|c|}
\hline & & & Mothers & 282 & 1.65 & 0.74 & 0.94 & 0.34 & 0.37 & -1.26 \\
\hline & & W3 & Fathers & 165 & 1.62 & 0.78 & 1.08 & 0.47 & 0.55 & -1.14 \\
\hline & & & Mothers & 282 & 1.46 & 0.67 & 1.36 & 1.42 & 0.84 & -0.74 \\
\hline \multirow[t]{6}{*}{7} & \multirow{6}{*}{$\begin{array}{l}\text { I wish my } \\
\text { child is } \\
\text { different }\end{array}$} & W1 & Fathers & 166 & 1.08 & 0.42 & 5.60 & 32.85 & 4.88 & 23.79 \\
\hline & & & Mothers & 279 & 1.04 & 0.22 & 5.51 & 32.99 & 5.02 & 24.67 \\
\hline & & W2 & Fathers & 166 & 1.05 & 0.34 & 6.85 & 49.66 & 6.14 & 38.14 \\
\hline & & & Mothers & 282 & 1.06 & 0.25 & 4.36 & 19.94 & 4.02 & 15.02 \\
\hline & & W3 & Fathers & 166 & 1.02 & 0.19 & 8.68 & 80.69 & 7.93 & 64.87 \\
\hline & & & Mothers & 282 & 1.04 & 0.25 & 8.68 & 85.90 & 7.13 & 54.36 \\
\hline \multirow[t]{6}{*}{8} & \multirow{6}{*}{$\begin{array}{l}\text { I feel } \\
\text { protective } \\
\text { toward my } \\
\text { child }\end{array}$} & W1 & Fathers & 165 & 1.20 & 0.59 & 3.42 & 12.12 & 2.70 & 6.50 \\
\hline & & & Mothers & 281 & 1.12 & 0.40 & 3.84 & 16.48 & 3.15 & 9.14 \\
\hline & & W2 & Fathers & 166 & 1.25 & 0.54 & 2.37 & 5.75 & 1.83 & 2.06 \\
\hline & & & Mothers & 282 & 1.15 & 0.47 & 3.74 & 15.92 & 2.88 & 7.67 \\
\hline & & W3 & Fathers & 166 & 1.24 & 0.57 & 2.87 & 9.18 & 2.06 & 3.35 \\
\hline & & & Mothers & 282 & 1.12 & 0.46 & 4.80 & 25.38 & 3.72 & 14.03 \\
\hline \multirow[t]{6}{*}{9} & \multirow{6}{*}{$\begin{array}{l}\text { I wish I did } \\
\text { not have } \\
\text { my child }\end{array}$} & W1 & Fathers & 166 & 1.05 & 0.29 & 7.77 & 70.82 & 6.02 & 39.63 \\
\hline & & & Mothers & 280 & 1.10 & 0.43 & 5.25 & 30.15 & 4.20 & 18.02 \\
\hline & & W2 & Fathers & 166 & 1.05 & 0.30 & 7.20 & 62.03 & 5.49 & 32.93 \\
\hline & & & Mothers & 282 & 1.10 & 0.38 & 4.94 & 28.60 & 3.84 & 14.92 \\
\hline & & W3 & Fathers & 166 & 1.06 & 0.36 & 7.11 & 53.94 & 6.01 & 37.93 \\
\hline & & & Mothers & 282 & 1.09 & 0.37 & 5.21 & 31.46 & 4.09 & 17.07 \\
\hline \multirow[t]{6}{*}{10} & \multirow{6}{*}{$\begin{array}{l}\text { Close to } \\
\text { child }\end{array}$} & W1 & Fathers & 166 & 1.42 & 0.68 & 1.45 & 1.19 & 1.07 & -0.42 \\
\hline & & & Mothers & 280 & 1.32 & 0.65 & 2.22 & 4.72 & 1.65 & 1.42 \\
\hline & & W2 & Fathers & 166 & 1.54 & 0.78 & 1.33 & 0.96 & 0.86 & -0.76 \\
\hline & & & Mothers & 282 & 1.23 & 0.59 & 2.85 & 8.02 & 2.29 & 4.06 \\
\hline & & W3 & Fathers & 166 & 1.36 & 0.61 & 1.69 & 2.42 & 1.22 & 0.02 \\
\hline & & & Mothers & 282 & 1.12 & 0.40 & 3.73 & 15.99 & 2.99 & 8.19 \\
\hline
\end{tabular}

MIBS- $J$ = Japanese modification of the mother-to-infant bonding scale; $\mathrm{W} 1=5$ days after childbirth; W2 $=1$ month after childbirth; W3 $=4$ months after childbirth. Skewness after log transformation $>4.0$ or kurtosis after log transformation $>15.0$ is presented in boldface; $n=166$ for fathers and 282 for mothers.

Table 2 Factor loadings of four MIBS-J items for each factor within different models 


\begin{tabular}{|c|c|c|c|}
\hline \multicolumn{3}{|c|}{ MIBS-J item } & \multirow{2}{*}{$\begin{array}{l}\text { Model } 1 \\
\text { (1-factor) }\end{array}$} \\
\hline & & & \\
\hline & & & I \\
\hline \multirow[t]{6}{*}{1} & \multirow[t]{6}{*}{ I feel loving toward my child } & \multirow{2}{*}{$\begin{array}{l}\text { W1 fathers }(n=166) \\
\text { mothers }(n=282)\end{array}$} & 0.69 \\
\hline & & & 0.70 \\
\hline & & \multirow[t]{2}{*}{ W2 } & 0.81 \\
\hline & & & 0.85 \\
\hline & & \multirow[t]{2}{*}{ W3 } & 0.71 \\
\hline & & & 0.76 \\
\hline \multirow[t]{6}{*}{6} & \multirow[t]{6}{*}{ I enjoy doing things with my child } & \multirow[t]{2}{*}{ W1 } & 0.75 \\
\hline & & & 0.57 \\
\hline & & \multirow[t]{2}{*}{ W2 } & 0.59 \\
\hline & & & 0.54 \\
\hline & & \multirow[t]{2}{*}{ W3 } & 0.61 \\
\hline & & & 0.53 \\
\hline \multirow[t]{6}{*}{8} & \multirow[t]{6}{*}{ I feel protective toward my child } & \multirow[t]{2}{*}{ W1 } & 0.58 \\
\hline & & & 0.65 \\
\hline & & \multirow[t]{2}{*}{ W2 } & 0.74 \\
\hline & & & 0.66 \\
\hline & & \multirow[t]{2}{*}{ W3 } & 0.79 \\
\hline & & & 0.65 \\
\hline \multirow[t]{6}{*}{10} & \multirow[t]{6}{*}{ I feel close to my child } & W1 & 0.68 \\
\hline & & & 0.68 \\
\hline & & W2 & 0.65 \\
\hline & & & 0.68 \\
\hline & & W3 & 0.75 \\
\hline & & & 0.64 \\
\hline
\end{tabular}

MIBS-J = Japanese modification of the mother-to-infant bonding scale; $W 1=5$ days after childbirth; W2 = 1 month after childbirth; W3 = 4 months after childbirth; $n=166$ for fathers and 282 for mothers. Factor loadings $>0.30$ are presented in boldface; the upper figure in each cell represents factor loading (or total variance explained) among fathers, whereas the lower figure in each cell represents factor loading (or total variance explained) among mothers. Item scores after log transformation were entered into an exploratory factor analysis.

Table 3 Factor loadings of three MIBS-J items for each factor within different models 


\begin{tabular}{|c|c|c|c|}
\hline \multicolumn{3}{|c|}{ MIBS-J item } & \multirow{2}{*}{$\begin{array}{l}\text { Model } 1 \\
\text { (1-factor) }\end{array}$} \\
\hline & & & \\
\hline & & & I \\
\hline \multirow[t]{6}{*}{1} & \multirow[t]{6}{*}{ I feel loving toward my child } & \multirow{2}{*}{$\begin{array}{l}\text { W1 fathers }(n=166) \\
\text { mothers }(n=282)\end{array}$} & 0.65 \\
\hline & & & 0.75 \\
\hline & & \multirow[t]{2}{*}{ W2 } & 0.81 \\
\hline & & & 0.90 \\
\hline & & \multirow[t]{2}{*}{ W3 } & 0.75 \\
\hline & & & 0.84 \\
\hline \multirow[t]{6}{*}{6} & \multirow[t]{6}{*}{ I enjoy doing things with my child } & \multirow[t]{2}{*}{ W1 } & 0.77 \\
\hline & & & 0.55 \\
\hline & & \multirow[t]{2}{*}{ w2 } & 0.56 \\
\hline & & & 0.48 \\
\hline & & \multirow[t]{2}{*}{ W3 } & 0.65 \\
\hline & & & 0.50 \\
\hline \multirow[t]{6}{*}{8} & \multirow[t]{6}{*}{ I feel protective toward my child } & \multirow[t]{2}{*}{ W1 } & 0.59 \\
\hline & & & 062 \\
\hline & & \multirow[t]{2}{*}{ W2 } & 0.76 \\
\hline & & & 0.65 \\
\hline & & \multirow[t]{2}{*}{ W3 } & 0.73 \\
\hline & & & 0.59 \\
\hline
\end{tabular}

MIBS-J = Japanese modification of the mother-to-infant bonding scale; $\mathrm{W} 1=5$ days after childbirth; W2 = 1 month after childbirth; W3 $=4$ months after childbirth; $n=166$ for fathers and 282 for mothers. Factor loadings $>0.30$ are presented in boldface; the upper figure in each cell represents factor loading (or total variance explained) among fathers, whereas the lower figure in each cell represents factor loading (or total variance explained) among mothers. Item scores after log transformation were entered into an exploratory factor analysis.

Table 4 Measurement and structural invariance of three MIBS-J items between fathers and mothers 


\begin{tabular}{|c|c|c|c|c|c|c|c|c|c|c|}
\hline Models & & $x^{2}$ & $d f$ & $\chi^{2} / d f$ & $\Delta \chi^{2}(d f)$ & CFI & $\triangle \mathrm{CFI}$ & RMSEA & $\triangle \mathrm{RMSEA}$ & Judgement \\
\hline \multirow{5}{*}{$\begin{array}{l}\text { W1 } \\
\text { fathers vs. } \\
\text { mothers }\end{array}$} & Configural & 0 & 0 & 0 & Ref & 1.000 & Ref & & Ref & Accept \\
\hline & Metric & 4.041 & 2 & 2.020 & 4.041(2) NS & .929 & 0.011 & 0.048 & 0.048 & Accept \\
\hline & Scalar & 11.540 & 5 & 2.308 & 7.499(3) NS & .902 & 0.027 & 0.054 & 0.006 & Accept \\
\hline & Residual & 67.547 & 15 & 4.503 & $\underset{\star \star \star \star}{23.041(4)}$ & .847 & 0.055 & 0.089 & 0.006 & Accept \\
\hline & $\begin{array}{l}\text { Factor } \\
\text { variance }\end{array}$ & 67.744 & 16 & 4.234 & $0.197(1) \mathrm{NS}$ & .849 & +0.002 & 0.085 & $\Delta 0.004$ & Accept \\
\hline \multirow{5}{*}{$\begin{array}{l}\text { W2 } \\
\text { fathers vs. } \\
\text { mothers }\end{array}$} & Configural & 0 & 0 & & Ref & 1.000 & Ref & & Ref & Accept \\
\hline & Metric & 3.286 & 2 & 1.643 & $3.286(2) \mathrm{NS}$ & .995 & 0.005 & 0.038 & 0.038 & Accept \\
\hline & Scalar & 3.715 & 5 & 0.743 & $0.429(3) \mathrm{NS}$ & 1.000 & +0.005 & 0.000 & $\Delta 0.038$ & Accept \\
\hline & Residual & 5.731 & 8 & 0.716 & $2.016(3) \mathrm{NS}$ & 1.000 & 0 & 0.000 & 0 & Accept \\
\hline & $\begin{array}{l}\text { Factor } \\
\text { variance }\end{array}$ & 6.022 & 9 & 0.669 & $0.291(1) \mathrm{NS}$ & 1.000 & 0 & 0.000 & 0 & Accept \\
\hline \multirow{4}{*}{$\begin{array}{l}\text { W3 } \\
\text { fathers vs. } \\
\text { mothers }\end{array}$} & Configural & 0 & 0 & & Ref & 1.000 & Ref & & Ref & Accept \\
\hline & Metric & 1.276 & 2 & 0.638 & $1.276(2) \mathrm{NS}$ & 1.000 & 0 & 0.000 & 0.000 & Accept \\
\hline & Scalar & 14.800 & 5 & 2.960 & $\begin{array}{l}13.524(3) \\
\star \star\end{array}$ & .964 & 0.036 & 0.067 & 0.067 & Accept \\
\hline & Residual & 67.874 & 8 & 8.484 & $\underset{* \star \star}{53.074(3)}$ & .783 & 0.181 & 0.130 & 0.063 & Reject \\
\hline
\end{tabular}

MIBS- $J$ = Japanese modification of the mother-to-infant bonding scale; Ref = reference; $\mathrm{CFI}=$ comparative fit index; RMSEA = root mean square error of approximation; W1 = 5 days after childbirth; W2 $=1$ month after childbirth; W3 = 4 months after childbirth; $\mathrm{n}=350$ for fathers and 543 for mothers. ${ }^{+}$inadmissible solution; ${ }^{\star} p<.05,{ }^{\star \star} p<.01, \star \star \star p<.001$.

Table 5 Measurement and structural invariance of three MIBS-J items across the three time points 


\begin{tabular}{|c|c|c|c|c|c|c|c|c|c|c|}
\hline Models & & $x^{2}$ & $d f$ & $\chi^{2} / d f$ & $\Delta \chi^{2}(d f)$ & $\mathrm{CFI}$ & $\Delta \mathrm{CFI}$ & RMSEA & $\triangle \mathrm{RMSEA}$ & Judgement \\
\hline Fathers & Configural & 0 & 0 & & Ref & 1.000 & Ref & & Ref & \\
\hline \multirow{5}{*}{$\begin{array}{l}\text { W1 vs. } \\
\text { W2 vs. } \\
\text { W3 }\end{array}$} & Metric & 11.250 & 4 & 2.813 & $\begin{array}{l}11.250 \\
(4)^{*}\end{array}$ & .987 & 0.013 & 0.042 & 0.042 & Reject \\
\hline & $\begin{array}{l}\text { Metric } \\
\text { (partial } \\
\text { invariance) } \\
\text { item } 1\end{array}$ & 9.938 & 2 & 4.969 & $\underset{\star \star}{9.938}(2)$ & .985 & 0.002 & 0.062 & 0.020 & Reject \\
\hline & $\begin{array}{l}\text { Metric } \\
\text { (partial } \\
\text { invariance) } \\
\text { item } 6\end{array}$ & 5.721 & 2 & 2.856 & $5.529(2)$ & .993 & +0.006 & 0.042 & 0.000 & Accept \\
\hline & Scalar & 23.686 & 10 & 2.369 & $\begin{array}{l}17.965 \\
(8) *\end{array}$ & .975 & 0.018 & 0.036 & $\Delta 0.006$ & Accept \\
\hline & Residual & 39.691 & 16 & 2.481 & $\begin{array}{l}16.005 \\
(6) \text { * }\end{array}$ & .957 & 0.018 & 0.038 & 0.002 & Reject \\
\hline \multirow{5}{*}{$\begin{array}{l}\text { Mothers } \\
\text { W1 vs. } \\
\text { W2 vs. } \\
\text { W3 }\end{array}$} & Configural & 0 & 0 & & Ref & 1.000 & Ref & & Ref & \\
\hline & Metric & 1.880 & 4 & 0.470 & $\begin{array}{l}1.880(4) \\
\text { NS }\end{array}$ & 1.000 & 0 & 0.000 & 0.000 & Accept \\
\hline & Scalar & 55.910 & 10 & 5.591 & $\underbrace{54.03(6)}_{\star \star \star}$ & .950 & 0.050 & 0.053 & 0.053 & Reject \\
\hline & $\begin{array}{l}\text { Scalar } \\
\text { (partial) item } \\
1\end{array}$ & 54.097 & 8 & 6.762 & $\underset{\star \star \star \star}{52.217(2)}$ & .950 & 0.050 & 0.060 & 0.060 & Reject \\
\hline & $\begin{array}{l}\text { Scalar } \\
\text { (partial) item } \\
6\end{array}$ & 55.471 & 8 & 6.934 & $\underset{\star \star \star \star}{53.591(2)}$ & .948 & 0.052 & 0.060 & 0.060 & Reject \\
\hline
\end{tabular}

MIBS-J = Japanese modification of the mother-to-infant bonding scale; ${ }^{+}$inadmissible solution; Ref = reference; $\mathrm{CFI}=$ comparative fit index; RMSEA = root mean square error of approximation; $\mathrm{W} 1$ = 5 days after childbirth; $\mathrm{W} 2=1$ month after childbirth; $\mathrm{W} 3=4$ months after childbirth; $\mathrm{n}=350$ for fathers and 543 for mothers. ${ }^{\star} p<.05,{ }^{\star \star} p<.01,{ }^{\star \star \star} p<.001$.

\section{Supplementary Files}

This is a list of supplementary files associated with this preprint. Click to download.

- Additionalfile1.doc

- Additionalfile2.doc 